\title{
4.1.5 HYDROPHILIC COATING MATERIALS
}

\author{
H. Schneider, N. Niegisch, M. Mennig, H. Schmidt
}

\section{INTRODUCTION}

Hydrophilic as well as hydrophobic surfaces offer advantages for cleaning of technical surfaces. The following properties of hydrophilic coatings are interesting: less dirt, easy to clean, antifogging and inhibition of growth for vegetation and bacteria. Particularly the soiling of a transparent surface causes light scattering and lots of brilliancy. The good wettability by water (very thin water film, no formation of water drops) of hydrophilic coatings inhibits the scattering of light and prevents fogging on the surface. The resulting very glossy and clean surface reduces also the growth of microorganisms.

Freshly manufactured glass surfaces possess high hydrophilic properties, i.e. contact angles against water of $<20^{\circ}$. Due to contaminations by the ambient air (adsorption of oils, fats, proteins, dirt particles), the surface turns to a hydrophobic character, which leads to contact angles against water between 60 to $70^{\circ}$. This leads to an increased fogging of a transparent material (glass or plastics) and the incident light is strongly scattered (e.g. raindrops on an automotive windscreen). The hydrophilic surface initiates also a good water run-off. So the growing of bacteria is strongly restricted. This property is not only important for glass applications, but is more and more demanded by air conditioning manufacturers (e.g. for evaporators of automotive systems).

Under static conditions, the contact angle $\Phi$ (figure 1) is used to determine the wettability of a solid material by a liquid. The smaller its value, the more a given volume of liquid spreads on a solid surface.

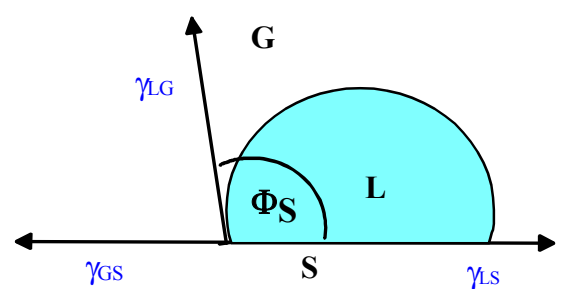

$$
\cos \Phi_{S}=\frac{\gamma_{G S}-\gamma_{L S}}{\gamma_{L G}} \quad \text { Young-Dupré }
$$

Figure 1. Wettability of a solid surface by a liquid (left); Young-Dupré equation (right). 
188 Sol-gel technologies for glass producers and users

The Young-Dupré equation [1,2] is obtained from a balance of forces along the solid surface at the contact line. The following constants represent the different interfacial tensions:

$\gamma_{\mathbf{G S}}:$ gas - solid interfacial tension

$\gamma_{\text {LS }}$ : liquid - solid interfacial tension

$\gamma_{\mathbf{L G}}:$ liquid - gas interfacial tension

$\Phi_{\mathrm{S}}$ : static contact angle

If the drop diameter is in the range of 2 to $6 \mathrm{~mm}$, the contact angle is independent of the drop size (static contact angle). The measurement is realized by applying a liquid drop on a solid surface with a syringe. The contact angle of the liquid is gradually minimized: the faster the time the more hydrophilic the solid surface is.

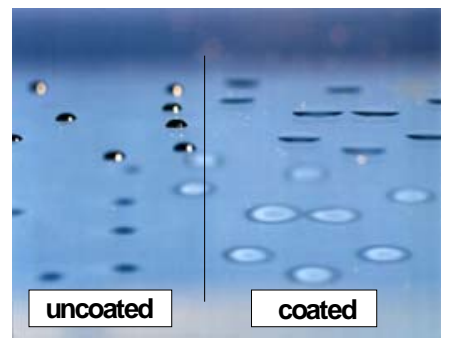

a)

b)

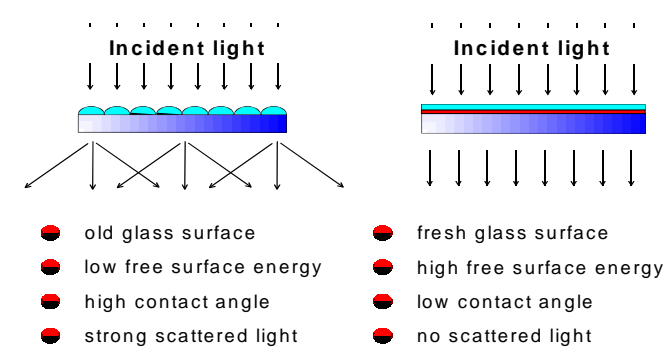

Figure 2. Water drops on a glass surface a) uncoated side: hydrophobic $\left(\Phi_{\mathrm{S}}=\right.$ $\left.65^{\circ}\right)$ and b) hydrophilic coated side $\left(\Phi_{\mathrm{S}}<10^{\circ}\right)$.

Hydrophilic coatings produced by the sol-gel process are easily applied on glass substrates by common coating techniques like spraying, dipping, flooding, spinning etc. The final curing of the dried coating is possible under rather mild conditions and can be done photochemically and/or thermally.

Potential fields of application for hydrophilic / antifogging coatings on glass are innumerable: bathroom mirrors, eye-glasses, optical lenses, covers for headlights, outdoor floor lights, automotive mirrors (inside, outside), instruments in humid environments (inside) and other vehicle windows (inside, outside), etc.

One can differentiate between two kinds of hydrophilic systems: a) surfactant-based hydrophilic coatings (described in section 2), b) photocatalytic coatings (described in section 3). 


\section{SURFACTANT-BASED HYDROPHILIC SOL-GEL COATING MATERIAL}

Surfactants are surface active agents which reduce the tension between two immiscible systems. They are composed of a hydrophobic and hydrophilic part (figure 3) and are divided in four classes, depending on their hydrophilic groups: 1. anionic surfactants: negatively charged in aqueous solution, very often sulphonate, sulphate or phosphate groups.

2. cationic surfactants: positively charged in aqueous solution, the main components being quaternary ammonium compounds.

3. amphoteric surfactants: contain both anionic and cationic parts in the same molecule which cannot be separated by dissociation.

4. non-ionic surfactants: no formation of ions in aqueous solution; the hydrophilic part are OH-groups, ethylene oxide or propylene oxide chains.

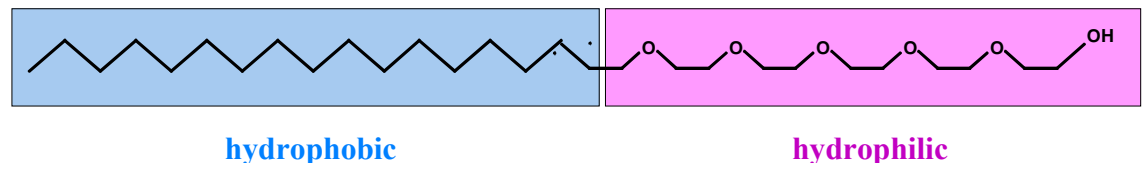

Figure 3. Typical chemical structure of a non-ionic surfactant.

There have been many attempts in the past to develop surfactant based hydrophilic coatings, especially for automotive applications by different glass companies and research groups [3-10]. However all of them suffered from low scratch hardness and too fast leaching by water exposure. Therefore, it can be stated, that presently surfactant-based hydrophilic coating materials are not suitable for an outdoor use, because the leaching of surfactant molecules under intensive water treatment like rain is important (loss of long time hydrophilicity). In this case photocatalytically active $\mathrm{TiO}_{2}$-coating seems to be the best system (see section 3).

Different approaches have been followed for the development of permanent hydrophilic coatings on glass. Very often transparent anti-fogging coatings based on polyurethane (PU) were used [11]. Due to the polar structure of these polymers, a relatively high water adsorption is possible. This leads to a swelling of the coating after water exposure involving a frequent release of the layers during long term water treatment. The low scratch hardness of PU is also a problem for most applications.

Other kinds of UV-curable anti-fogging coatings are made with acrylate based polymers [12]. After curing, the hydrophilic components (OH groups of hydroxyethyl methacrylate, methyl cellulose) are enriched at the surface due to thermodynamic forces, while the non polar components migrate to the non polar PMMA surface. A further improvement of the hydrophilic properties was achieved by addition of a polyalcohol diepoxide [13]. Such layers do not show any fogging at $100 \%$ humidity and $60^{\circ} \mathrm{C}$ within 10 hours. The surfactant molecules are delivered subsequently to the surface by diffusion, resulting in a "re- 
newal" of the hydrophilic surface. The scratch and abrasion resistance of such coatings are often not sufficient enough for many applications.

The hydrophilic effect can be further increased by incorporation of diffusible surfactants into the above-mentioned materials caused by the thermodynamically controlled enrichment of hydrophilic end groups at the surface. Adsorbed hydrophobic particles as well as the surfactants present on the surface can be easily removed with water, whereby the surfactants from the bulk move subsequently to the surface by a diffusion process, so that a "renewing" of the hydrophilic surface is obtained ("controlled release mechanism"), until the reservoir of diffusible surfactants from the bulk is used up.

Such kind of coating material consists for instance of bifunctional aliphatic isocyanides (e.g. hexamethylene diisocyanide) as well as poly-functional polyalcohols and ionic or non-ionic surfactants (e.g. ethoxylated fatty alcohols), whereby non-ionic surfactants are preferred, due to their diffusible behavior [14]. The manufactured layers show anti-fogging characteristics and have an improved scratch and abrasion resistance compared with usual transparent polymers.

Another example describes a transparent coating material, based on polyvinylpyrrolidone/polydimethacrylamide-copolymers with polymerizable $\alpha$-unsaturated groups as well as polyisocyanates and non-ionic or anionic surfactants [15]. The best hydrophilic properties were achieved both by the use of anionic surfactants, which are chemically bound to the hydrophilic network, and non-ionic surfactants, which remain diffusible in the matrix. The coatings show excellent adhesion on different substrates (glass, polycarbonate, polyester, PMMA, PU, etc.) and typical uses are on eyeglasses. There is no fogging observed even if they are first cooled down to $0^{\circ} \mathrm{C}$ and than exposed to air with $100 \%$ humidity. After 20 cycles, no reduction of the anti-fogging properties is found, but the scratch hardness is not strong enough.

New inorganic-organic nanocomposite materials are synthesized mainly via the sol-gel process by controlled hydrolysis and condensation reactions of organo-metallic compounds from $\mathrm{Si}, \mathrm{Ti}, \mathrm{Zr}, \mathrm{Al}$ alkoxides [16-18]. Various organic groups can be introduced into the inorganic network by using organically modified alkoxides or by addition of commercially available organic monomers or dissolved polymers. These organic groups can act as network modifiers for the inorganic network or as network formers after a polymerization step. The incorporation of monodisperinorganic psed, nanoscaled $(<20 \mathrm{~nm})$ hard articles increases dramatically the scratch and abrasion resistance in comparison to unmodified inorganic-organic composites $[9,10]$. Due to their small dimension of about $5-20 \mathrm{~nm}$, the particles practically do not scatter the light and therefore do not decrease the transparency of the coatings.

The inorganic-organic nanocomposite route was further developed to synthesize "smart coatings" with gradients of functionalized components. The principle was already adapted to hydrophilic coatings. Hydrophilic inorganic-organic nanocomposites coating materials were synthesized via sol-gel process for contact lenses already at the beginning of the 80's [21,22]. However the swelling of 
these materials by water results in a softening of the coating and in a significant reduction of the mechanical stability.

Further investigations showed that it is possible to improve the mechanical properties of these coatings significantly by adding nanoscaled particles while keeping their hydrophilic properties. These systems contain a combination of covalently bonded surfactants for a certain basic hydrophilicity and diffusible surfactants to achieve a durable effect even when the coating is soiled [23]. The bondable surfactants possess double bonds which can react after initialization with the sol-gel matrix. The fixation of the surfactants takes place during thermal or photochemical induced cross-linking reaction. The concentration of the used surfactants in the sol can be varied between 3 and 8 weight $\%$. A greater amount of surfactants leads to coatings with worse mechanical properties. Systems with 6 and more weight $\%$ surfactants show water contact angles hardly measurable $\left(<10^{\circ}\right)$.

A water-based nanostructured sol-gel material can also be used as a hydrophilic coating material, which is particularly suitable for the application on glass substrates. The material is characterized by the fact, that the solvent proportion (alcohols) in the liquid lacquer amounts to less than $10 \%$. The viscosity of the lacquer can be adjusted by diluting with water. This base lacquer can be used as anti-fogging coating material by bringing in hydrophilic components (e.g. bondable and/or diffusible surfactants) [24,25].

\section{PHOTOCATALYTIC HYDROPHILIC TiO - MATERIAL}

$\mathrm{TiO}_{2}$ is known as a semi-conducting material that can catalyze chemical reactions under UV light irradiation [26,27]. The mechanism is shown in figure 4.

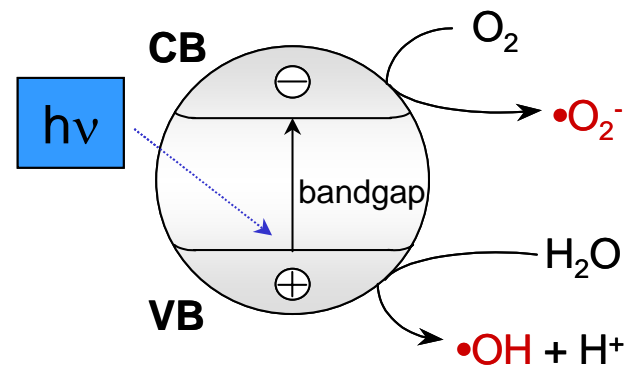

Figure 4. Mechanism of the photocatalytic effect.

In its most active anatase modification electrons from the valence band are excited into the conduction band by UV light irradiation with a wavelength $<388$ $\mathrm{nm}$. These electrons are transferred to oxygen molecules and the holes in the valence band are filled with electrons from water molecules transforming both molecules into radicals. As one result of this reaction the surface of the $\mathrm{TiO}_{2}$ coating is covered by $\mathrm{OH}$-groups leading to a super-hydrophilicity with contact angle $<10^{\circ}[26,27]$. If the coating is left in contact with the surrounding atmos- 
phere without UV irradiation for a long time, it is contaminated by particulate pollutants and becomes hydrophobic (figure 5).

contaminated surface

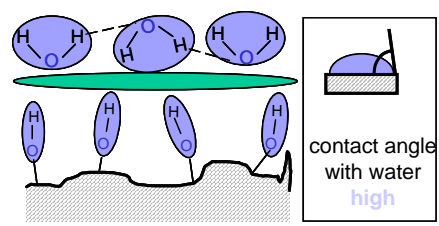

cleaned surface

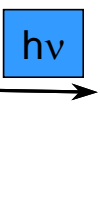

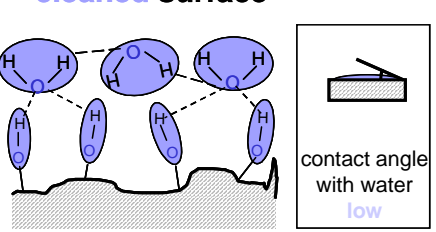

Figure 5. Self-cleaning process by the photocatalytic effect of a $\mathrm{TiO}_{2}$ surface.

The self-cleaning process of such a contaminated surface is shown in figure 5. The high reactive particles can attack the organic substances in the soiling and oxide them especially at the interface between coating and soiling. This process leads to a loss of adhesion and the soil can be easily washed off by rainwater. The resulted surface is hydrophilic again. The expenditure in time, energy and cost to carry out the cleaning of facades, roofs, etc. can be therefore reduced by a hydrophilic inorganic coating made of $\mathrm{TiO}_{2}$. To achieve this objective on surfaces like glass, ceramics, plastics, textiles, paper, etc., a universal coating system is necessary. State-of-the-art systems [28-31] are still today not ideal.

Titanium dioxide in the rutile phase is a commercial product synthesized by a sulphate or chloride process and used as white pigment. For photocatalytic application the more active anatase phase is used being kinetically stable at temperatures below $900^{\circ} \mathrm{C}$. To achieve a high surface area with transparent coatings, the particles have to be as small as possible. Commercially available nanoscaled particles like P25 (Degussa) are synthesized by the aerosil-process. However the small primary particles tend to agglomerate during the synthesis process so that it is not possible to get transparent coatings.

State of the art application methods need high temperatures $\left(>400^{\circ} \mathrm{C}\right)$ to form the anatase modification in situ during the coating and/or densification process, which restricts their application to high temperature stable substrates. A known process to produce transparent coatings is the deposition of coatings from the gas phase (CVD/PVD, plasma polymerization, etc.). This process is very expensive. Additionally the applied film is amorphous, so that a sintering process $\left(>400^{\circ} \mathrm{C}\right)$ is needed to form the anatase phase [32].

The synthesis of $\mathrm{TiO}_{2}$ via sol-gel process has several advantages: By specific selection of the synthesis parameters, a great number of nucleation sites can be created. The final particle size can be limited by adding a surface modifier which stops the crystal growth after a definite time and prevents also the nanoparticles from agglomeration.

To get transparent coatings crystalline $\mathrm{TiO}_{2}$ nanoparticles were synthesized via a combined sol-gel and lyothermal route [33]. The crystalline anatase particles show a narrow size distribution in the range of 8 to $10 \mathrm{~nm}$. After surface 
modification with different silanes the particles can be redispersed in organic solvents. Standard wet application techniques like spray, dip or spin coating can be used to apply transparent coatings with a contact angle against water $<10^{\circ}$. The deposition of flexible separation layer may be needed as adhesion promoter, as a barrier layer for the prevention of the migration of low-molecular substrate components into the titania layer and as a protection layer against the degradation of the organic substrates [34-37].

\section{REFERENCES}

1. T. Young, Philos. Trans. R. Soc. London 95, 65, 1805

2. R. Knapikowski, U. Messow, K. Quitzsch, H.-G. Hauthal, Wetting behavior of the binary system water sodiumdodecylsulfate on solid surfaces, Chem. Technik, 44, Heft 10 (1992), 339

3. H. Radisch, W. Scholz, Transparent, anti-fogging coating comprised of plastic material containing a surface active agent, US 4609688 (1986)

4. R. Parker, J. Howes, Coated articles and methods for the preparation thereof, US 4844983, 1989

5. S. Watanabe, I. Ibuki, Polyisocyanate composition having high emulsifiability and stability, and aqueous coating composition comprising the composition, US 5852111 (1998)

6. J. Kaetsu, M. Yoshida, New coating materials and their preparation by radiation polymerization antifogging coating composition, Journal of Applied Polymer Science, 24 (1) (1979), 235

7. R. Kasemann, H. Schmidt, Coatings for mechanical and chemical protection based on organicinorganic sol-gel nanocomposites, New Journal of Chemistry, 18 (10), (1994) 1117

8. J.R. Kleer, Aqueous compositions containing colloidal silica and compounds with alkoxysilane and/or silanol groups, US 6063863 (2000)

9. J.M. Bravet, Process for producing a transparent polyurethane film with energy-absorbing and antifogging properties, US 5116442 (1992)

10. R. Neeb, Beschichtungszusammensetzung mit beschlagverhindernden Eigenschaften, Patent DE 10002059A1 (2001)

11. Prolan Oberflächentechnik GmbH, Schwäbisch Gmünd, Transparent Antifog coating for Polycarbonate, Company brochure

12. Y. Yamamoto, H. Doya, T. Izumi, K. Kumazawa, H. Ohmura, Y. Oshibe, Anti-fogging resin film-forming composition, EP 339909 (1989)

13. Y. Oshibe, K. Kumazawa, Y. Yamamoto, H. Omura, Ultraviolet ray curing type coating composition and preparation of ultraviolet ray cured film, JP 3247672 (1991)

14. H. Raedisch, W. Scholz, Transparent, anti-fogging coating comprised of plastic material containing a surface active agent, US 0004609688A

15. W. S. Creasy, Transparent anti-fog coating compositions, US 4467073 (1984)

16. H. Schmidt, Grundlagen und Anwendungsmöglichkeiten von ORMOCERen In: Proceedings Symposium Materialforschung 1988, Bd.1, Hrgs.: B. Vierkorn-Rodolph, D. Lillak, PLR/KF Jülich, 722

17. H. Schmidt, Organically Modified Ceramics, Materials with "History" or "Future"?, In: Ultrastructure Processing Ceramics of Advanced Materials, John Wiley \& Sons, (1992) 409

18. H. Schmidt, D. Uhlmann, D. Ulrich (eds.), Thin films, the chemical processing up to gelation, Chemistry, Spectroscopy and Applications on Sol-Gel Glasses, Springer, Berlin (1992) 120

19. R. Kasemann, H. Schmidt, E. Wintrich, A new type of a sol-gel derived inorganic-organic nanocomposite, Mat. Res. Soc. Symp. Proc., 346, VI (1994) 915

20. R. Kasemann, H. Schmidt, In: First European Workshop on hybrid organic-inorganic materials (synthesis, properties, applications), 171 (1993)

21. H. Schmidt, G. Philipp, Inorganic/organic polymers for lenses by the sol-gel process, in: „Glass ... Current Issues“ by A. F. Wright, J. Dupuy (Eds.), Martinus Nijhoff Publishers, Dordrecht, Boston, Lancaster (1985) 580

22. H. Schmidt, G. Philipps, New materials for contact lenses prepared from Si- and Ti-Alkoxides by the sol-gel process, Journal of Non-Cryst. Sol., 63 (1984) 283 
194 Sol-gel technologies for glass producers and users

23. R. Kasemann, H. Schmidt, S. Brück, Functional coatings on glass surfaces by the sol-gel process Bol. Soc. Esp. Ceram. Vid., 31-C, vol. 7 (1992) 75

24. E. Arpac, G. Jonschker, H. Schirra, H. Schmidt, Nanostrukturierte Formkörper und Schichten und deren Herstellung über stabile wasserlösliche Vorstufen, DE 19816136 (1999)

25. E. Arpac, G. Jonschker, H. Schirra, H. Schmidt, Nanostructured forms and layers and method for producing them using stable water-soluble precursors, EP 1086162 (2001)

26. A. Fujishima, K. Hashimoto, T. Watanabe, $\mathrm{TiO}_{2}$ Photocatalysis, Fundamentals and Applications, BKC, Inc. (1999)

27. R. Wang, K. Hashimoto, A. Fujishima, M. Chikuni, E. Kojima, A. Kitamura, M. Shimohigoshi, T. Watanabe, Light-induced amphilic surfaces, Nature, 388 (1997) 431

28. A. Biedermann, Verfahren und Vorrichtung zum Aufbringen von transparenten Schutzschichten auf Gegenstände, danach hergestellte Gegenstände, Patent DE 19708808 (1998)

29. M. Hayakawa, M. Chikuni, T. Watanabe, Photocatalytic Functional Material and Method of Production thereof, Patent EP 792687 (1997)

30. R.J. Kostelnik, F.C. Wen, Very High Solids $\mathrm{TiO}_{2}$ Slurries, Patent WO 9957075 (1999)

31. P. Boire, X. Talpaert, Photocatalytic Coating Substrate, Patent WO 9710186 (1997)

32. A. Biedermann, Leicht zu reinigende und selbstreinigende glatte Oberflächen, Keramische Zeitschrift, 51 (1999) 874

33. N. Niegisch, M. Akarsu, Z. Csögör, M. Ehses, H. Schmidt, $\mathrm{TiO}_{2}$ nanoparticle coatings for selfcleaning and antimicrobial application, Proceedings of Hygienic Coatings Conference, paper 20 (2002)

34. H. Schmidt, M. Mennig, Th. Burkhart, C. Fink-Straube, G. Jonschker, M. Schmitt, A. Bauer, Verfahren zur Herstellung von funktionellen glasartigen Schichten, INM-Patent EP 729442 (1996)

35. G. Jonschker, PhD Thesis, INM and University of Saarland, Saarbruecken/Germany (1998)

36. M. Mennig, G. Jonschker, H. Schmidt, Verfahren zur Herstellung von Glassubstraten mit verbesserter Langzeitstandfähigkeit bei erhöhten Temperaturen, INM-Patent EP 642475

37. M. Mennig, G. Jonschker, H. Schmidt, Verfahren zur Herstellung von Glassubstraten mit verbesserter Langzeitstandfähigkeit bei erhöhten Temperaturen, INM-Patent WO 93/24424 (1993) 